\title{
Improving Engineering Ethics of Professional Engineers in Sri Lanka - Perspectives of Young Engineers
}

\author{
D.P.S. Wijesinghe, H.A.D. Saumyadi and V.P.T. Jayawardane
}

\begin{abstract}
Doing things right is an essential requirement of any profession in the world. Ethics guide professionals to achieve that. Engineering Ethics, which is supposed to be abided by professional engineers, has become a sensitive topic in the industry with rapid globalization. Today, engineers confront numerous ethical issues in the fast-moving world, which is never before. However, it is not an excuse to work unethically. Engineering Ethics should be promoted among engineers, and their ethical behaviour should be enhanced in the present world to face ethical dilemmas successfully. In such a situation, this study was conducted to identify the ways to improve the ethical behaviour of engineers within the context of Sri Lanka. Data were collected from a conveniently selected sample of young engineers in Sri Lanka through a self-administered online questionnaire as an opinion survey. The qualitative content analysis technique was employed inductively to achieve the objective. Approximately 200 responses were received from a sample of 500 engineers. Analysis of the responses has identified the following major categories. $57.5 \%$ of responses recommend that it requires proper education and training on Engineering Ethics to improve the ethical behaviour of Sri Lankan engineers. $22.8 \%$ of responses recommend carrying out a system change in the existing socio-economic environment in Sri Lankan industrial sector. In comparison, $19.7 \%$ of responses highlighted the necessity of enforcing and empowering Engineering Ethics and their practice in Sri Lanka. Stakeholders of the engineering profession can incorporate the study's findings at the policy level to improve the ethical behaviour of engineers. Collecting data only from young engineers in Sri Lanka whose industrial experiences were less than ten years without considering the opinions of senior engineers can be identified as a significant limitation of this study.
\end{abstract}

Keywords: Behavior, Content analysis, Engineering ethics, Engineers, Sri Lanka

\section{Introduction}

Engineers contribute to the economic development of the country by various means utilizing their expertise. In today's world, their contributions span a wider area from nanoscale equipment to skyscrapers. Formal engineering knowledge and industrial experience gained over time support them in making decisions. Tragic disasters such as the Kansas City Hotel walkway collapse, Bhopal gas tragedy, Challenger space shuttle explosion and the collapse of the Rana Plaza building in Bangladesh happened over time, causing the death of many innocent people. Such catastrophes emphasize that technical knowledge is not sufficient to make socially responsible engineering decisions. Engineering Ethics guide professional engineers to behave and make engineering decisions ethically. However, rapid technological developments happen in the world every second and socio, economic \& political constraints prevailing in the working environment act as barriers to the ethical conduct of technical professionals, including engineers. Engineers should be motivated to adhere to Engineering Ethics within their professional conduct to avoid reoccurrence of similar tragedies in the present and future society. It is a responsibility of all the stakeholders of the engineering profession such as professional organizations, universities, regulatory bodies, government and every individual engineer in the society.

Eng. D.P.S. Wijesinghe, AMIE(SL), AEng, B.Sc. Eng.

Hons (Moratuwa), PhD(Reading),

Lecturer, Department of Interdisciplinary Studies,

University of Ruhuna,

Email:praneeth@is.ruh.ac.lk

(D) https://orcid.org/0000-0001-5746-9510

Eng. (Ms). H.A.D. Saumyadi, AMIE(SL), AEng,

B.Sc.Eng. Hons (Moratuwa), PhD(Reading),

Production Engineer, Beira Brush Private Limited.

Email:danusisaumyadi@gmail.com

(iD) https://orcid.org/0000-0001-8224-2609

Eng. (Dr.) (Mrs). V.P.T. Jayawardane, AMIE(SL), AEng,

B.Sc Eng (New Zealand), LLB(Hons)(London), MA, MPhil,

$P h D$, Senior Lecturer, Department of Industrial

Management, University of Moratuwa.

Email:thesaraj@uom.lk

(iD) https://orcid.org/0000-0002-0493-114X 
The objective of this study was to identify how to improve the ethical behaviour of engineers in the Sri Lankan context by collecting opinions from young engineers working in Sri Lanka.

\section{Literature Review}

\subsection{Engineering Ethics}

Ethics can be defined as moral philosophy, which recommends concepts of right and wrong conduct for professionals practising within a profession [1]. Philosophy contains three major subject areas relevant to ethics as meta-ethics, normative ethics and applied ethics. Ethics of professions belong to the subject area of normative ethics, which describe real-world concerns like moral standards in which society decides to standardize right and wrong behaviour [2]. Every profession should have moral standards specifically developed to guide the behaviour of its members. Medical practitioners have their ethical guidelines developed over time to ensure moral conduct while treating patients. Medical Ethics is only applicable to medical practitioners and not to anybody else.

Similarly, Engineering Ethics was developed over time with the contribution of various professional engineering organizations targeting engineering practitioners. It can be defined as "the discipline or study of moral issues arising in and surrounding engineering" [3]. Society started to think about the ethical issues in engineering practice since the invention of dynamite in 1867 by Alfred Nobel [4]. Engineering Ethics which was started to develop with that point, now discusses various spectrums not limited to the areas such as health, safety, welfare, sustainability, honesty, integrity, confidentiality, corruption, conflict of interest and whistleblowing [5].

\subsection{Codes of Engineering Ethics}

There is no single internationally accepted guideline as Engineering Ethics for all engineering practitioners in the world. Professional engineering associations established considering territorial and engineering discipline wise factors worldwide have introduced specific codes of Engineering Ethics targeting their members. Codes of Engineering Ethics can be defined as principles that refer to a fundamental and comprehensive doctrine regarding the behaviour and conduct of engineering professionals [1]. Professional engineering associations like the American Society of Civil Engineers (ASCE), American
Society of Mechanical Engineers (ASME), National Society of Professional Engineers (NSPE) and the Institution of Electrical \& Electronics Engineers (IEEE) were foremost in developing codes of ethics for their members in the late $19^{\text {th }}$ century [6]. Initially, those codes of ethics were majorly concerned about the involvement of engineers in businesses and their obligations towards employers with lesser attention on service to the public and safety. During the last few decades, this imbalance was fixed with the raised concerns of the public on the safety of engineering products and services [7]. These codes of ethics are revised from time to time based on various requirements of professional societies and the general public. However, these codes are not equivalent to each other and consistent with many similarities and dissimilarities. As an example, a comparison of NSPE and IEEE codes of ethics reveals a few crucial aspects. IEEE code does not emphasize the engineers' responsibility towards their employers, while NSPE does. NSPE code is a very detailed one, and hence its members can follow the guidelines conveniently with specific cases while IEEE is not.

Nowadays, there are professional engineering associations established country-wise as the Institution of Engineers in Sri Lanka (IESL), the Institution of Engineers Australia (IEAust) and the Institution of Engineers India (IEI) etc. to uplift the professionalism of the engineering profession while resolving the emerging professional issues particular to those countries. IESL is the apex body for professional engineers in Sri Lanka. It was incorporated in 1968 as the successor to the then Engineering Association of Ceylon, founded in 1906 and currently has a code of Engineering Ethics developed considering the professional practice of Sri Lankan engineers [8]. IESL code of ethics has been developed considering various clauses available in international professional engineering associations like IEEE, ASCE and NSPE etc. Recently established Engineering Council Sri Lanka (ECSL) is acting as the regulatory body for registering practising engineering professionals, including chartered engineers, associate engineers, affiliate engineers, incorporated engineers, engineering diplomates and engineering technicians in Sri Lanka [9]. ECSL is also having a code of ethics for its members. One of the significant responsibilities of ECSL is the maintenance of professional standards and conduct of engineering practitioners in Sri Lanka. Like NSPE and IEEE codes of ethics, IESL has a more 
detailed and specific code of ethics compared with ECSL code of ethics.

The code of ethics itself has several drawbacks. When the code becomes detailed and longer, it is less likely to be read and explicitly understood by the engineers. When the code becomes shorter and concise, engineers must do more imagination before deciding as the clauses are vague [7]. Apart from that, many engineers have not taken the membership of relevant professional associations in most countries. Since such memberships are not compulsory to practice engineering, most of them are not taking the memberships. Hence, non-members have lesser attention to the codes of ethics of those associations. In Sri Lanka, ECSL is trying to resolve those issues to some extent. Additionally, many engineers face various internal conflicts when carrying out their tasks as per the relevant code of ethics if there is no hierarchical indication of the importance of each clause of ethics. However, IESL has given priority to holding the health, safety and welfare of the public. Another controversial concern is the less involvement of professional engineering associations in safeguarding the engineers who acted according to the codes of ethics from the discriminatory practices of their employers for being ethical [3]. These concerns have moved engineers away from ethical behaviours to some extent.

\subsection{Engineering Ethics Education}

With the current requirements for accrediting engineering degrees worldwide, teaching Engineering Ethics has become an essential criterion to get those degrees accredited [10]. Based on this requirement, state universities that offer engineering degree programs in Sri Lanka teach ethics-related subjects to their undergraduates to prepare them to face ethical issues successfully. IESL also, as the apex body of professional engineers in Sri Lanka, conducts continuing professional development courses for practising engineers in Sri Lanka to raise their awareness on ethically sensitive matters [10].

With the attainment of professional recognition for Engineering Ethics, wider attention is received to teach ethics [11]. The majority of the international studies on Engineering Ethics is focused on pedagogy [11]-[15]. Most of the studies recommend carrying out Engineering Ethics education, not as stand-alone courses, but as technical course modules embedded with ethical aspects (ethics across the curriculum) [16].

\subsection{Research on Engineering Ethics}

Since Engineering Ethics is not a purely technical oriented subject area, engineers and scholars have paid less attention to systematic studies. Nowadays, many valuable textbooks are available globally, which have been written focussing on various theoretical and practical aspects of Engineering Ethics [4]. Lack of scholarly examinations on ethics in practice is a barrier to the continuous enhancement of the existing knowledge base of Engineering Ethics. Barry and Herkert [16] has recommended that carrying out research linked to the instruction, retention, and practical application of Engineering Ethics requires continued backing, ongoing assessment, and continued dissemination of findings.

Only very few studies related to Engineering Ethics have been carried out in Sri Lanka [17], [18]. Consequently, Sri Lankan engineering students and practising engineers are experiencing difficulties finding such resources to gain more insights specific to the Sri Lankan context. In such a situation, conducting a study to identify the ways to improve the ethical behaviour of Sri Lankan engineers is a timely requirement, that is beneficial to both professional engineers and all the stakeholders of the engineering profession, to promote ethical practice.

\section{Methodology}

Subject areas which lack previous systematic academic studies have to be studied qualitatively to uncover hidden insights within the various contexts [19]. Hence, it was decided to gather opinions from practising engineers in the Sri Lankan context on improving the ethical behaviour of engineers in Sri Lanka as a qualitative survey. Following a convenient sampling approach, a self-administered online open-ended question was sent as an email to over 500 young engineers who were within the professional networks of authors. The openended question was also accompanied by a few other questions to collect their demographic information. Approximately 200 participantgenerated textual responses were anonymously received within two weeks. Hence, there were a large number of textual data for analysis. Therefore, the content analysis technique was used as the analysis technique, determining trends and patterns of words used, frequency, 
and relationships from a massive amount of textual data [20].

All the textual responses were uploaded to NVIVO qualitative data analysis software. The qualitative content analysis technique was used inductively during the analysis step. As the first step of the analysis, responses were read several times to familiarize with the data. Then, the open coding process was started to create categories relevant to the responses and categories were grouped into major categories with the support of NVIVO. The inductive approach let the researchers look into the data with a fresh mind with lesser influence from the extant literature during the coding process [20]. Responses belonging to each category were quantified as a percentage out of all responses received. The outcomes were discussed among the research team to enhance the rigour of the study.

\section{Results \& Discussion}

Two hundred and two numbers of responses were received from the engineers for the shared questionnaire. Engineers who responded to this questionnaire are named as 'respondents' hereafter in this text. The demographic information of the respondents is as shown in Figure 1 and Figure 2.

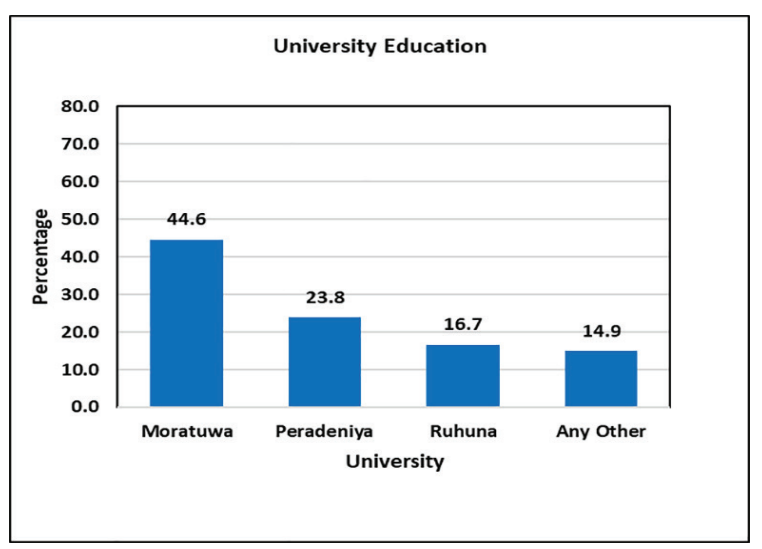

\section{Figure 1 - University where Respondents Completed Undergraduate Studies}

Respondents have completed their undergraduate engineering education at major state universities in Sri Lanka like Moratuwa, Peradeniya and Ruhuna. 44.6\%, 23.8\% and $16.7 \%$ of respondents have studied in these universities, respectively. The rest of the respondents $(14.9 \%)$ have completed their undergraduate education at other universities.

As authors have conveniently selected the sample from their professional networks, all the respondents can be identified as young engineers in Sri Lanka. The industrial experience of respondents were less than ten years.

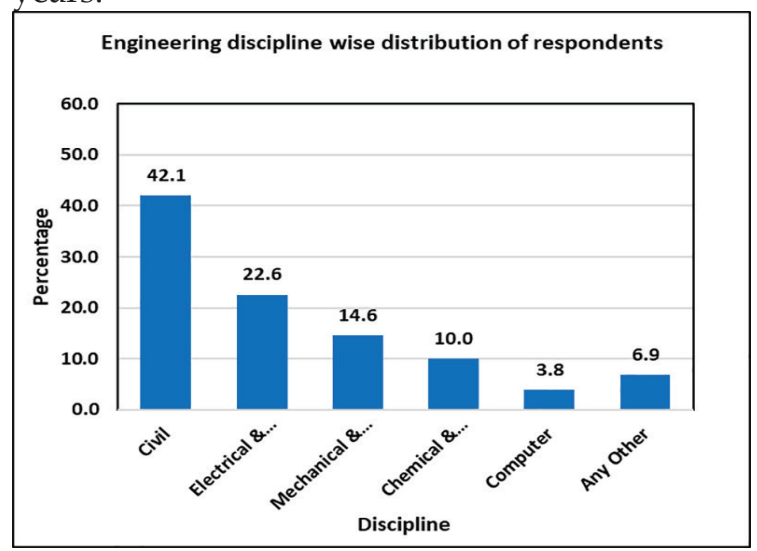

Figure 2 - Engineering Discipline wise Distribution

$42.1 \%$ of respondents were civil engineers, while $22.6 \%$ of respondents belonged to electrical \& electronics engineering. $14.6 \%$ of respondents were mechanical and production engineers, while $10.0 \%$ of respondents belonged to chemical and materials engineering. Out of the respondents, only $3.8 \%$ were computer and software engineers. $6.9 \%$ of respondents did not belong to any of the disciplines mentioned above.

Figure 3, illustrated below, shows the sectorwise employment of respondents. The majority of the respondents $(60 \%)$ worked in the private sector. In comparison, $26.7 \%$ were employed in the state sector organizations. $8.7 \%$ of respondents were employed as university academics while only $1 \%$ were self-employed in the industry.

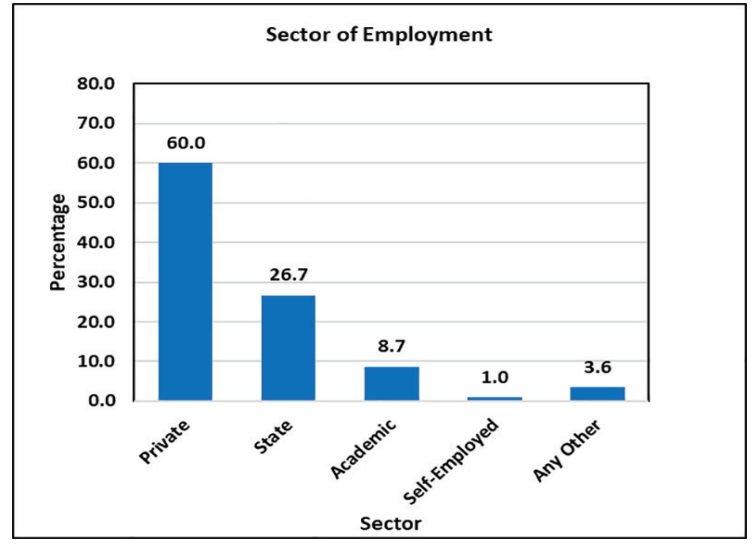

Figure 3 - Sector wise Employments of Respondents

From here onwards, the results of the research will be discussed. 
Inductive content analysis of the textual responses uncovers the following significant categories as suggestions to improve ethical behaviour of engineers in Sri Lanka, quantified as percentages of responses belonging to each major category.

Table 1 - Major Categories \& Percentages

\begin{tabular}{|l|l|}
\hline \multicolumn{1}{|c|}{ Main Category } & Percentage of responses \\
\hline Proper Education \& Training & $57.5 \%$ \\
\hline Socio-Cultural Change & $22.8 \%$ \\
\hline Empowering \& Enforcement & $19.7 \%$ \\
\hline
\end{tabular}

In the following sections, each major category and associated sub-categories are discussed with the support of excerpts from engineers' responses.

\subsection{Proper Education \& Training}

$57.5 \%$ of responses have recommended the requirement of proper education and training on Engineering Ethics for engineers in Sri Lanka. As mentioned in the literature review, ethics related subjects are taught as stand-alone subjects in the state sector universities which offer engineering degree programs. In addition to that, IESL conducts CPD courses on Engineering Ethics for practising engineers in Sri Lanka. Respondents believe that engineers need proper education and training on Engineering Ethics than the existing practices.

It can be identified from the responses received for this research that universities should pay their attention to improve Engineering Ethics education for their engineering undergraduates. A respondent has mentioned, "There is not enough subject content included in Engineering degree programs related to ethical behaviours; hence engineers get experienced once they are in the industry or other working place. It is better if we can include more ethical behaviour subjects to our degree programs (at least before industrial training programs)". According to that excerpt, it is clear that ethics education should not be limited to one credit or two credit module for the entire four years. There should be more subjects related to ethics and ethical behaviour included in local engineering degree programs. He or she has identified the requirement of learning Engineering Ethics by undergraduates before starting their industrial training. Then only they will get to know how to behave in the industry ethically. If they do not have the proper knowledge to decide ethical and unethical practices, they will adopt every industrial practice of their superiors as ethical practices. Another respondent has stated his or her opinion as "Should practice it in the university during the entire degree. Generalize the engineering ethics. Competition of the university will reduce the importance of ethics". This highlights the requirement of ethics across the curriculum for engineering undergraduates [16]. It is a widely accepted pedagogical model in western countries. Another thing is, Sri Lankan students currently experience a huge competition during their school education to get higher results. During the undergraduate period, there is a possibility of demonstrating unfair competitive behaviours to achieve various things like higher results, good job opportunities etc. It deteriorates the ethical behaviours of students to some extent paving the way for more and more unethical acts in future. Therefore, ethics should be practised within the university during the entire four years of the degree. Another important response was, "Systematically it should be learnt using university compulsory modules. And it should be evaluated anyhow and give more value to ethical people and ethical thinking". Currently, universities check the technical knowledge of their undergraduates through various kinds of examinations. However, there are no precise cut mechanisms to evaluate undergraduates' ethical behaviour and ethical thinking within the university. If such an approach exists, university students will focus much on improving their ethical behaviour since it is valuable for their degree program.

Not only subject knowledge but also regular discussion on Engineering Ethics is essential as per the responses received for this study. A respondent has mentioned that "It is like a culture. Individually we cannot improve it. As a profession, we can improve it by having awareness programmes in a repetitive manner using a body like IESL". There should be proper awareness sessions organized to improve the awareness of practising engineers on ethics. Professional engineering associations like IESL could do that. Engineering Ethics should become like a culture among engineers. It can be implemented by holding formal awareness sessions continuously. Another important response was, "Updating them about the Code of Ethics will be a good idea as some engineers may not remember the points of Code of Ethics". The Code of ethics for any profession should not be just a document to keep on the wall or upload on the website of any professional organization to show off the code of ethics [2]. It should be a live document that should be practised from the heart of the professionals. Regular discussions and awareness sessions will make it 
live and more practicable. A respondent has also highlighted, "Engineers should have continuous interaction with the IESL and other relevant institutions/societies and update their knowledge with the industry. Also, they should follow Engineering Ethics, and the responsibility to the society should be the first, rather than earning money". Discussions with senior engineers in Sri Lanka have revealed that young engineers' involvement with IESL is comparably more minor nowadays. However, if young engineers can participate and be involved with IESL activities more and more, IESL can support them to build their professional, ethical life.

Proper guidance and training on ethics received from senior engineers is an essential requirement to improve the ethical behaviour of engineers through the major category of education and training. A respondent has highlighted that "Engineers need very good ethical training not only exams and presentations. Young engineers should be guided and observed properly by senior engineers". Young engineers need proper guidance on ethical practices, especially within the initial stages of their career life, from the senior engineers. Senior engineers in the industry have a higher responsibility to uplift the ethical practices of their subordinate engineers. Another respondent has mentioned that "As an Engineer in the construction field, I believe senior engineers have a responsibility to guide and advise young engineers and to encourage them. Usually, all engineers are focused only on progress and quality of execution work. But personal development and ethical behaviours of young engineers are not encouraged in the field". This response highlights a critical concern that prevails in various industrial sectors in Sri Lanka. Similarly, another respondent has emphasized that "Senior engineers should be exemplary to their juniors". All engineers have an ethical responsibility to properly guide his or her subordinate engineers to enhance knowledge and experience [8]. It includes guiding subordinate engineers to work and behave ethically in the industry. Senior engineers cannot advise on ethical behaviour to his or her subordinates while doing evil things. They should work as exemplary role models in the industry. Otherwise, there is a higher tendency of adopting unethical practices by younger engineers in the industry. Another response says, "At the company level, seniors should spend some time to change the juniors' attitudes towards ethical practices...and top management should appreciate and promote those activities...".
Most respondents have highlighted that ethical behaviour cannot be infused into the daily lifestyles of engineers through a few years of education and training. They highlighted that ethics should be taught and practised from early childhood to infuse ethics into the personalities of any professional. A respondent has highlighted, "It should come from their childhood. Not only Engineers, but every citizen should also act and live honestly. We have a good culture in Sri Lanka, and we need to maintain it through our entire life". Similarly, another response says, "Teach them from childhood; otherwise it is difficult to change them". However, as educated professionals, engineers have a higher capability to identify good and bad, not like uneducated people. Another response directs the attention once again towards the universities. A respondent has the opinion that "Although there is a code of ethics for Engineers in Sri Lanka, it is not correctly practised by the engineers. Hence according to my opinion, engineers should start the practice of ethical behaviour from their university period". As per that recommendation, engineers should start practising Engineering Ethics while they study in universities.

\subsection{Changing the Existing Socio-Cultural Environment in Industrial Sector}

Secondly most highlighted category of recommendation based on the received responses is incorporating changes to the existing socio-cultural environment in the Sri Lankan industrial sector to improve the ethical behaviour of engineers. Favourable environments motivate the ethical behaviours of any professionals.

According to the responses, they have highlighted the requirement of fair treatment for engineers in Sri Lanka. A respondent has stated an existing controversy in the industry as "Want to make the same salary scale and the same facilities with the experience and talent. Then only all will think about career and Ethics. Engineers are getting really low salaries here compared to other professions. Getting a little salary and asking for career development and ethics is a joke. All need money for an MSc, for a CPD or travel for them". The salary issue of engineers is a controversial and debatable point to discuss here, which needs further attention of all the stakeholders of the engineering profession. Another response highlights the same issue as "A social-political change is highly required. When it comes to government engineers, the salary they get is not enough. So how can they maintain their living standards? That is why most of the engineers tend to 
accept bribes. So finally the solution would be a change for current social/political and economic system". Political intervention in engineering decision making should be avoided to facilitate the ethical practice of engineers. This response highlights that requirement as "Intervention of corrupt politicians in decision making (persuasion) and could be many other specific reasons which have led these officers to be unethical. After that, a sound mechanism to address and cope with the reasons behind unethical practices of engineers should be implemented". As highlighted, a mechanism should be implemented to investigate about unethical practices of engineers and causes for such behaviours to avoid repetition of such practices in the industry.

Organizational cultures of some companies have demotivated engineers to be ethical. A respondent has mentioned that "Some company seniors expect engineers to know everything, and humiliate them when they fail to answer some questions. This is seen in some major local companies. Training is important, which most local companies invest very little in. Further, engineers should be appreciated rather than exploiting their efforts". Such environments will motivate engineers to do unethical things to sustain themselves in the workplace. Engineering employers should focus on this matter critically to change this culture. In addition to that, the existing competitive education system in Sri Lanka should be changed. Otherwise, there will be highly educated professionals in Sri Lanka without having any sense of ethics. This response highlights the requirement as "With a competition based education system where children are chased every day to pass exams and not allowed to develop with basic human values, there is no hope for a country with people with no basic understanding of ethics". Another engineer has recommended an overall change in the existing social system in Sri Lanka which is not favourable for ethical engineering practice as "This system should be changed to make a better engineer, until that you will get more causes of engineering ethics violations".

Social and cultural change is not sufficient to establish an ethical working culture for the engineering profession. Engineering professionals should have a supportive attitude towards Engineering Ethics. Hence, few engineers have recommended an attitudinal change among engineers. A respondent has highlighted it as "Attitude, passion towards the engineering profession needs to be improved. 'This is not a job this is a profession, this attitude will increase the ethical behaviour". Engineering is not a mere occupation to earn an income to live. There are various professional responsibilities associated with it towards society [2]. Ethical responsibility is a major aspect among them. Hence, engineers should understand that requirement and discharge their duties ethically, changing their unsuitable attitudes and perceptions towards the engineering profession. Another response emphasizes this as "I think; first engineers should strongly believe in their morals. The change should start individually." Individually, engineers are responsible for being the change agent in society without pointing out various excuses for carrying out unethical acts.

As the responses imply, Sri Lankan society needs significant attitudinal, social and cultural change to improve the ethical behaviour of engineers while going against unethical practices of others.

\subsection{Empowering and Enforcing Engineering Ethics}

The least highlighted category of recommendation revealed from this study is empowering and enforcing Engineering Ethics. $19.7 \%$ of responses belonged to this category. This is because codes of Engineering Ethics and legal regulations are two different concepts. People who violate codes of ethics are not brought to courts and put on trial to give punishments like imprisonment in the case of violations of legal regulations [21]. Professional organizations who laid down these codes of ethics have the power to conduct investigations on ethical violations and remove them from the membership of those organizations if the investigation identifies the particular person is guilty of that situation. Removing an engineer from the members' directory was not a considerable punishment for those engineers since such memberships were not compulsory to practise as engineers in Sri Lanka up to the recent past.

Several respondents have requested to enforce the code of Engineering Ethics with proper legal support to take actions against people who violate ethics and people who instruct to violate ethics during engineering practice. The following recommendation can be highlighted. "Engineers (or any employee) may be forced to make an unethical decision by the hierarchy. In such a situation, the laws and regulations of the country should support the engineer/employee to make an ethical decision, and protect from any hostile reprisal by the management". Similarly, another 
respondent has emphasized it as "There should be proper standards in the country's system regarding ethical practices. A systematic change is required $\mathcal{E}$ the government should enforce laws to improve the engineer's adherence to ethical practices". As highlighted, there should be a proper institutional and legal support system to safeguard the engineers who act ethically in professional activities as some employers consider the ethical acts of their engineers as disobedience to their hierarchical commands and later discriminate against such engineers for their ethical behaviour, forcing them to leave such organizations or ultimately firing them [3]. This can be considered a significant drawback in the code of ethics that demotivate engineers' adherence. Another important response that needs the engineering community's attention is "Engineers in Sri Lanka are part of Sri Lanka. So behaviours should adapt accordingly. Improving is adopting. Do research, suggest methods to get the thing done, change old guidelines copied from Europe. Prepare something that can work in Sri Lanka. Enforce and help engineers to follow them".

Some respondents have highlighted the need for more regulations on engineering practice as it is required to ensure the ethical conduct of engineers. A respondent has stated that "Ethics can be improved with having a non-political or nonbiased body like ECSL and impose strict rules against violation of Engineering ethics that are being practised at present scenario". A similar response describes it as follows. "If anyone requires to practice engineering in Sri Lanka, they should be registered with the engineering board, and they should be monitored by the engineering board for their ethical behaviour. Same way, companies should register in the engineering board to practice engineering in Sri Lanka, and ethical guidelines should be prepared for registered companies as well". Recently established ECSL has that responsibility and enforced legal status to maintain regulations relevant to engineering practice in Sri Lanka. All engineering practitioners in Sri Lanka should be registered at the Engineering Council, Sri Lanka, under Section 15 or 18 of the Engineering Council, Sri Lanka Act No 4 of 2017 in the Parliament of Democratic Socialist Republic of Sri Lanka [9]. This can be considered as a good initiation that happened in the Sri Lankan engineering sector. To get a membership at ECSL, engineers should have a membership with IESL. Therefore, any engineer who has been removed from the membership of IESL due to a violation of the code of Engineering Ethics will not get the opportunity to apply for the ECSL membership.
This approach will force all the engineers to maintain their professional conduct as per the code of ethics of IESL.

Some respondents have emphasized the requirement of strict monitoring and punishment procedure for engineers who violate the code of ethics in Sri Lanka. Such a response is "Strict monitoring mechanism should be established and should motivate other fellow engineers to point out the wrongdoings committed by the engineers". A monitoring mechanism should be developed considering the opinions of the entire engineering community. However, pointing out unethical acts of fellow engineers can be considered as an excellent suggestion to implement. Still, it should be implemented within the respective engineering community (eg-within the company) without tarnishing the reputation of others. Another respondent has stated that "Engineers who purposely violate these ethics clauses should be penalized regardless of their position". As per the responses, it is clear that there should be a proper mechanism to punish engineers who violate the code of ethics.

Excerpts of the responses given by the engineers give valuable insights on how to improve the ethical behaviour of engineers in Sri Lanka. Only selected responses were included here as there is a limitation on the length of this article. By including those selected excerpts within the text, which highlight the major categories of recommendations, authors have allowed respondents to disclose their concerns and opinions on Engineering Ethics. All the stakeholders of the engineering profession, including individual engineers, should pay their attention to improve the ethical behaviour of the engineering community. Policymakers can utilize these findings to incorporate policy-level decisions to create an ethical engineering practice in Sri Lanka.

\section{Conclusions}

Young engineers in Sri Lanka have recommended that the ethical behaviour of Sri Lankan engineers can be improved by 1 ). establishing a proper education and training system on Engineering Ethics, 2). changing the existing socio-cultural environment in the industrial sector into a favourable environment for Engineering Ethics, and 3). empowering and enforcing Engineering Ethics. Young engineers' recommendations raise the awareness of the engineering community on various aspects 
relevant to the current practices of engineers based on Engineering Ethics. Implementation of those recommendations is a timely requirement within the Sri Lankan industrial sector to build a more ethical and sustainable engineering practice.

Utilizing only the suggestions and opinions given by young engineers in Sri Lanka to arrive at above conclusions can be considered as a significant limitation of this study. A more accurate conclusion could achieve if a sample of senior engineers and four to five numbers of IESL council members are also included in this study.

Further research on this topic should be conducted focusing on both young and senior engineers in Sri Lanka employing qualitative and quantitative approaches. A more generalizable outcome can be achieved by conducting a quantitative study considering a random sample from the entire engineering community in Sri Lanka based on the findings of previous qualitative studies conducted on this topic. Salary issue of the Sri Lankan engineers is essential to be further investigated deeply to solve the ethical issues associated with it.

\section{Acknowledgement}

The authors wish to thank all the young engineers in Sri Lanka who voluntarily participated in this research.

\section{References}

1. Hansen, K. L., and Zenobia, K. E. “C h a p t e r 3," in Civil Engineer's Handbook of Professional Practice, John Wiley \& Sons, Inc, 2011, pp. 6393.

2. Harris, C. E. J., Pritchard, M. S., and Rabins, M. J., Engineering Ethics, Concepts and Cases, Fourth Edi. Belmont: WADSWORTH CENGAGE Learning, 2009.

3. Martin, M. W., and Schinzinger, R., Introduction to Engineering Ethics, 2nd Editio. McGraw Hill Higher Education.

4. B. g Blundell, Ethics in Computing, Science \& Engineering; A Student's Guide to Doing Things Right. Springer Nature Switzerland, 2020.

5. Shuriye, A. O., "Understanding Engineering Ethics," IIUM Eng. J., Vol. 12, No. 5, pp. 213218, 2011, doi: 10.1136/ard.60.90003.iii 43.
6. Tilley, M., and Abbasi, R. A., "Evolution of Engineering Ethics during the Last 150 Years," J. Prof. Issues Eng. Educ. Pract., Vol. 129, No. July, pp. 131-135, 2003, doi: doi:10.1061/(asce)1052-3928(2003)129:3(132).

7. Fleddermann, C. B., Engineering Ethics, $4^{\text {th }}$ Editio. Prentice Hall, 2012.

8. "The Institution of Engineers Sri Lanka - Code of Ethics," 2013. http://www.iesl.lk/page1541842 (accessed Dec. 15, 2018).

9. "Engineering Council Sri Lanka - ECSL code of ethics," 2020. https://www.ecsl.lk/code-ofethics (accessed Oct. 09, 2020).

10. "The Institution of Engineers Sri Lanka Accreditation of Engineering Degrees," 2013. http://www.iesl.lk/page-1668326 (accessed Dec. 15, 2018).

11. Khulief, Y. A., "ETHICS EDUCATION FOR ENGINEERING STUDENTS," in 2nd Conference of Planning $\mathcal{E}$ Development of Education and Scientific Research in the Arab States, 2008, Vol. 2, No. February 2008.

12. Van De Grift,T., Dillon,H., and Camp,L., "Changing the Engineering Student Culture with Respect to Academic Integrity and Ethics," Sci. Eng. Ethics, Vol. 23, No. 4, pp. 1159-1182, 2017, doi: 10.1007/s11948-016-98239.

13. McIntosh,T., Higgs, C., Mumford, M., Connelly, S., and DuBois, J., "Continuous Evaluation in Ethics Education: A Case Study," Sci. Eng. Ethics, Vol. 24, No. 2, pp. 727-754, 2018, doi: 10.1007/s11948-017-9927-x.

14. Bairaktarova, D., and Woodcock,A., "Engineering Student's Ethical Awareness and Behavior: A New Motivational Model," Sci. Eng. Ethics, Vol. 23, No. 4, pp. 1129-1157, 2016, doi: 10.1007/s11948-016-9814-x.

15. Balakrishnan, B., and Tarlochan,F. “Engineering Students' Attitude Towards Engineering Ethics Education," IEEE Glob. Eng. Educ. Conf. EDUCON, Vol. 2015-April, No. March, pp. 16-22, 2015, doi: 10.1109/EDUCON.2015.7095944.

16. Barry, B. E., and Herkert, J. R., "Engineering Ethics," in Cambridge Handbook of Engineering Education, A. Johri and B. M. Olds, Eds. Cambridge University Press, 2014.

17. Wijayasiri, P. A. I. A., "A Study of Professional Ethical Behaviour of Sri Lankan Software Engineers," University of Moratuwa, 2009. 
18. Wijesinghe, D. P. S., and Jayawardane, V.P.T., "Engineering Ethics- A Matter To Reconsider," in 1st South Asia Conference on Multidisciplinary Research, 2018, Vol. 1, No. January, pp. 95-100.

19. Cresswell, J. W., Research Design, $4^{\text {th }}$ Edition. Los Angeles: Sage Publications, Inc, 2014.

20. Vaismoradi, M., Turunen, H., and Bondas,T., "Content Analysis and Thematic Analysis: Implications for Conducting a Qualitative Descriptive Study," Nurs. Heal. Sci., Vol. 15, No. 3, pp. 398-405, 2013, doi: 10.1111/nhs.12048.

21. Starrett, S. K., Lara, A. L., and Bertha, C., Engineering Ethics-Real World Case Studies. Virginia: American Society of Civil Engineers, 2017. 